placebo, tanezumab $2.5 \mathrm{mg}$ or $5 \mathrm{mg}$ at baseline, wks 8 and 16. All treatments were given SC. AE data from the treatment period of each study were pooled for placebo, tanezumab $2.5 \mathrm{mg}$ and $5 \mathrm{mg}$ groups and examined by subgroups of gender, age and BMI. Data from the $10 \mathrm{mg}$ group of Study 1 were not included due to the low sample size.

Results: The incidence of any $\mathrm{AE}$ was numerically higher in females across treatment groups and in pts with a BMI $\geq 30 \mathrm{~kg} / \mathrm{m}^{2}$ in the tanezumab $5 \mathrm{mg}$, but not $2.5 \mathrm{mg}$ group, vs the overall population (Table 1 ). SAEs were infrequent but numerically higher across all tanezumab $5 \mathrm{mg}$ subgroups vs placebo (Table 2). Paraesthesia and hypoaesthesia were the most common AEs of APS and were increased in all tanezumab groups in the overall population vs placebo. In any of the subgroups, the incidence of paraesthesia or hypoaesthesia was $\leq 7.8 \%$ and $\leq 3.9 \%$, respectively. The difference within a patient subgroup for paraesthesia or hypoaesthesia was typically comparable with that of the overall population across treatments.

Table 1. Incidence of AEs during the treatment period

\begin{tabular}{lllll}
\hline \% of pts with an $\mathrm{AE}$ in each subgrou & $\begin{array}{c}\text { Placebo } \\
\mathrm{n}=586\end{array}$ & $\begin{array}{c}\text { Tanezumab } \\
2.5 \mathrm{mg} \\
\mathrm{n}=602\end{array}$ & $\begin{array}{c}\text { Tanezumab } \\
2.5 \mathrm{mg} / 5 \mathrm{mg} \mathrm{n}=219\end{array}$ & $\begin{array}{c}\text { Tanezumab } \\
5 \mathrm{mg} \\
\mathrm{n}=347\end{array}$ \\
\hline $\begin{array}{l}\text { Overall population } \\
\text { Gender }\end{array}$ & 51.7 & 52.3 & 47.0 & 54.8 \\
$\quad$ Male & 51.1 & 49.7 & 41.3 & 46.6 \\
$\quad$ Female & 52.0 & 53.6 & 50.4 & 59.0 \\
Age (years) & & & & \\
$\quad<65$ & 55.0 & 54.0 & 44.0 & 54.5 \\
$\geq 65$ & 47.2 & 50.0 & 52.6 & 54.9 \\
BMI $\left(\mathrm{kg} / \mathrm{m}^{2}\right)$ & 58.1 & 46.6 & 51.9 & 45.5 \\
$\quad<25$ & 51.4 & 55.9 & 43.7 & 50.0 \\
$25-<30$ & 49.2 & 51.5 & 43.2 & 58.9 \\
$30-<35$ & 52.7 & 52.3 & 55.3 & 60.9 \\
$\geq 35$ & & & & \\
\hline
\end{tabular}

BMI, body mass index; $\mathrm{kg} / \mathrm{m} 2$, kilogram per square metre

Table 2. Incidence of SAEs during the treatment period

\begin{tabular}{lllll}
\hline \% of pts with a SAE in each subgroup & $\begin{array}{c}\text { Placebo } \\
\mathrm{n}=586\end{array}$ & $\begin{array}{c}\text { Tanezumab } \\
2.5 \mathrm{mg} \\
\mathrm{n}=602\end{array}$ & $\begin{array}{c}\text { Tanezumab } \\
2.5 \mathrm{mg} / 5 \mathrm{mg}=219\end{array}$ & $\begin{array}{c}\text { Tanezumab } \\
5 \mathrm{mg} \\
\mathrm{n}=347\end{array}$ \\
\hline $\begin{array}{l}\text { Overall population } \\
\text { Gender }\end{array}$ & 1.5 & 2.2 & 1.4 & 2.6 \\
$\quad$ Male & 1.6 & 3.0 & 1.3 & 2.5 \\
$\quad$ Female & 1.5 & 1.7 & 1.4 & 2.6 \\
Age (years) & & & & \\
$\quad<65$ & 1.2 & 2.6 & 1.4 & 1.9 \\
$\geq 65$ & 2.0 & 1.6 & 1.3 & 3.1 \\
BMl (kg/m ${ }^{2}$ ) & 1.6 & 1.1 & 0 & 2.3 \\
$\quad<25$ & 1.6 & 2.7 & 0 & 2.7 \\
$25-<30$ & 1.6 & 2.0 & 1.4 & 3.1 \\
$30-<35$ & 1.3 & 2.3 & 4.3 & 1.6 \\
$\geq 35$ & & & & \\
\hline
\end{tabular}

BMI, body mass index; $\mathrm{kg} / \mathrm{m} 2$, kilogram per square metre

Conclusion: This pooled analysis showed that the safety profile of tanezumab in the subgroups studied is broadly similar to that of the overall study population. References:

[1] Schnitzer, T. J. et al. JAMA (2019)

[2] Birbara, C. et al. J Pain Res (2018)

Disclosure of Interests: Francis Berenbaum Grant/research support from: TRB Chemedica (through institution), MSD (through institution), Pfizer (through institution), Consultant of: Novartis, MSD, Pfizer, Lilly, UCB, Abbvie, Roche, Servier, Sanofi-Aventis, Flexion Therapeutics, Expanscience, GSK, Biogen, Nordic, Sandoz, Regeneron, Gilead, Bone Therapeutics, Regulaxis, Peptinov, 4P Pharma, Paid instructor for: Sandoz, Speakers bureau: Novartis, MSD, Pfizer, Lilly, UCB, Abbvie, Roche, Servier, Sanofi-Aventis, Flexion Therapeutics, Expanscience, GSK, Biogen, Nordic, Sandoz, Regeneron, Gilead, Sandoz, Alan Kivitz Shareholder of: AbbVie, Amgen, Gilead, GSK, Pfizer Inc, Sanofi, Consultant of: AbbVie, Boehringer Ingelheim,,Flexion, Genzyme, Gilead, Janssen, Novartis, Pfizer Inc, Regeneron, Sanofi, SUN Pharma Advanced Research, UCB, Paid instructor for: Celgene, Genzyme, Horizon, Merck, Novartis, Pfizer, Regeneron, Sanofi, Speakers bureau: AbbVie, Celgene, Flexion, Genzyme, Horizon, Merck, Novartis, Pfizer Inc, Regeneron, Sanofi, Thomas Schnitzer Consultant of: Pfizer, Lilly, AstraZeneca, GSK, Mark Brown Shareholder of: Pfizer Inc, Employee of: Pfizer Inc, Sean Donevan Shareholder of: Pfizer Inc., Employee of: Pfizer Inc., Anne Hickman Shareholder of: Pfizer Inc, Employee of: Pfizer Inc, Lars Viktrup
Shareholder of: Eli Lilly and Company, Employee of: Eli Lilly and Company, Christine West Shareholder of: Pfizer Inc, Employee of: Pfizer Inc, Takaharu Yamabe Shareholder of: Pfizer, Employee of: Pfizer

DOI: 10.1136/annrheumdis-2020-eular.3701

\section{FRI0393 BASELINE CHARACTERISTICS OF THE STUDY POPULATION IN ROCCELLA, A PHASE 2 CLINICAL TRIAL EVALUATING THE EFFICACY AND THE SAFETY OF S201086/GLPG1972 IN PATIENTS WITH KNEE OSTEOARTHRITIS}

K. Bernard ${ }^{1}$, S. Grankov ${ }^{1}$, M. Van der Stoep ${ }^{2}$, A. Lalande ${ }^{1}$, O. Imbert ${ }^{1}$,

D. Phung ${ }^{2}$, D. Chimits ${ }^{1}$, K. Muller ${ }^{2}$, E. Van der Aar ${ }^{2}$, H. Deckx ${ }^{2}$, M. Pueyo ${ }^{1}$,

F. Eckstein ${ }^{3,4} .{ }^{1}$ Institut de Recherches Internationales Servier, SURESNES,

France; ${ }^{2}$ Galapagos, Mechelen, Belgium; ${ }^{3}$ Institute of Anatomy \& Cell Biology,

Paracelsus Medical University, Salzburg, Austria; ${ }^{4}$ Chondrometrics Gmbh,

Ainring, Germany

Background: Osteoarthritis $(O A)$ is a degenerative joint disease involving structural pathology of all joint tissues, and most commonly affecting the knee, hip and hand. Degradation of the cartilage extracellular matrix represents a central feature of $O A$ and is widely thought to be mediated by proteinases that degrade primarily aggrecan and collagen. ADAMTS-5, a Disintegrin And Metalloproteinase with ThromboSpondin-motif-5, is a key aggrecan-cleaving enzyme involved in cartilage degradation. S201086/GLPG1972, a potent and highly selective inhibitor of ADAMTS-5, is an oral Disease-Modifying OsteoArthritis Drug (DMOAD) candidate.

Objectives: The primary objective of the ROCCELLA phase 2 clinical trial (NCT03595618) is to evaluate the effect of S201086/GLPG1972 over 52 weeks of treatment ( 3 dose groups compared to placebo) in reducing cartilage loss. Cartilage thickness of the knee is being measured quantitatively by Magnetic Resonance Imaging. Here, we describe the baseline characteristics of patients included in the ROCCELLA clinical trial.

Methods: The main inclusion criteria were: male or female, aged 40 to 75 , with a diagnosis of knee OA according to the clinical and radiological criteria of the American College of Rheumatology. The target knee had to meet a pain score between 40 and $90 \mathrm{~mm}$ on a $100 \mathrm{~mm}$ Visual Analog Scale (VAS), and the following radiographic feature upon central radiographic readings: Kellgren/Lawrence (KL) 2 or 3 and OARSI medial joint space narrowing (JSN) 1 or 2 (for more details see Deckx et al. OARSI 2020). The rationale for these specific radiographic inclusion criteria was to ensure sufficient cartilage loss over 12 months to assess the efficacy of S201086/GLPG1972.

Results: Across 12 countries, 3319 patients were screened and 932 were finally included in the study. The screen failure of $72 \%$ is mainly due to the radiological criteria. The age of the patients was $62.9 \pm 7.3$ years (mean \pm SD) with a majority of women $(69.3 \%)$. The BMI was $30.5 \pm 4.7 \mathrm{~kg} / \mathrm{m}^{2}$. The duration of knee OA was $7.2 \pm 6.9$ years. Five hundred and one $(53.8 \%)$ patients reported a medical history of musculoskeletal and connective tissue disorders, mainly osteoarthritis in other sites $(20.2 \%)$, back pain (13.6\%), and arthralgia (9.8\%). At inclusion, $97.2 \%$ of the patients were taking different types of drug treatments, mainly anti-inflammatory and anti-rheumatic products $(69.4 \%)$ and analgesics (42\%). At baseline, $11 \%$ of the target knees were $\mathrm{KL} 2$ and $89 \%$ were $\mathrm{KL} 3 ; 32 \%$ were OARSI medial JSN grade 1 and $68 \%$ grade 2 . Target knees at inclusion had a pain score on the VAS of $63.5 \pm 11.4 \mathrm{~mm}$ (range $0-100$, with 0 for no and 100 for extreme pain) and a total WOMAC (Likert 3.1) score of $48.0 \pm 15.0$ (range 0-96). The WOMAC subscores for pain, stiffness and physical function were $10.0 \pm 3.2$ (range 0-20), $4.2 \pm 1.6$ (range $0-8$ ) and $33.8 \pm 11.2$ (range $0-68$, indicating functional limitation), respectively.

Conclusion: For this clinical trial, patients were selected to present radiological criteria (i.e. OARSI JSN 1 and 2) to ensure sufficient structural progression (cartilage loss) over 12 months, as well as clinical symptoms. These stringent selection criteria were the main cause for the high screen failure rate. These baseline characteristics should warrant the ability to evaluate the efficacy of S201086/ GLPG1972 as a DMOAD candidate. The search for an effective pharmacological treatment that can prevent or cure OA remains a major challenge and unmet medical need.

Disclosure of Interests: Katy Bernard Employee of: Institut de Recherches Internationales Servier, Sergey GRANKOV Employee of: Institut de Recherches Internationales Servier, Marjolijne van der Stoep Employee of: Galapagos, Agnès Lalande Employee of: Institut de Recherches Internationales Servier, Olivier Imbert Employee of: Institut de Recherches Internationales Servier, De Phung Employee of: Galapagos, Damien Chimits Employee of: Institut de Recherches Internationales Servier, Karine Muller Employee of: Galapagos, Ellen van der Aar Employee of: Galapagos, Henri Deckx Employee of: Galapagos, Maria Pueyo Employee of: Institut de Recherches Internationales Servier, Felix Eckstein 
Grant/research support from: Merck, Orthotrphix, Servier, Galapagos, Kolon Tissuegene, Samumed, Novartis, Consultant of: Merck, Bioclinica, Servier, Samumed, Roche, Kolon Tissuegene, Galapagos and Novartis, Employee of: co-owner and employment with Chondrometrics

DOI: 10.1136/annrheumdis-2020-eular.3442

\section{FRI0394 1 MODERATE WEIGHT BEARING AND MINIMAL WEIGHT BEARING EXERCISE INDUCE ACUTE IMPACT ON COLLAGEN BIOCHEMICAL MARKERS RELATED TO OSTEOARTHRITIS IN HUMANS}

J. Bjerre-Bastos $^{1,2}$, H. B. Nielsen ${ }^{3}$, A. Mackey ${ }^{1}$, M. Karsdal ${ }^{4}$, A. C. Bay-Jensen ${ }^{4}$, J. R. Andersen5, M. Boesen ${ }^{6}, \mathrm{Y} . \mathrm{He}^{4}, \mathrm{~A}$. R. Bihlet ${ }^{2} .{ }^{1}$ University of Copenhagen, Copenhagen, Denmark; ${ }^{2}$ Nordic Bioscience Clinical Development, Herlev, Denmark; ${ }^{3}$ Sanos Clinic, Herlev, Denmark; ${ }^{4}$ Nordic Bioscience, Herlev, Denmark; ${ }^{2}$ Nordic Bioscience Clinical Development, Herlev, Denmark; ${ }^{6}$ Bispebjerg Hospital, Copenhagen, Denmark

Background: Exercise is recommended in osteoarthritis (OA) to limit pain and preserve joint function. Cycling is considered healthy, while the safety of running in OA has been controversial. The acute impact on cartilage in response to exercise (weight bearing vs non-weight bearing) remains to be explored.

Biomarkers originating from type I-III and VI collagen can be measured in serum and urine and may reflect cartilage turnover.

We report the first ever data on acute effects of exercise on a panel of collagen biomarkers in OA.

Objectives: To investigate the effect of running vs cycling on biomarkers of collagen type I-III and VI reflecting cartilage turnover.

Methods: We conducted a randomized, crossover clinical study (approval number: $\mathrm{H}-18038807$ ) of subjects with primary knee OA. Screening included a maximal heart rate test to standardize exercise intensity. Participants underwent 30 minutes of running and cycling on separate days with blood samples taken at baseline and 0.5, 1, 2 and 3 hours after exercise initiation and again 24 hours after the exercise in order to evaluate the dynamic levels of biomarkers. Urine samples were collected before exercise and approximately 1 hour and 24 hours after. Potential diurnal variation was taken into account by measurements at comparable times from participants on a separate day with no exercise (resting). Levels of serum CTX-I, C2M, C3M, C6M and urine CTX-II were measured by enzyme-linked immunosorbent assays.

Biomarker dynamics were plotted. Error bars represent 95\% CI. CTX-I and C6M are displayed.

Results: 20 subjects were included of which 20 completed cycling and resting and 15 completed running. Subject characteristics displayed in table.

CTX-I decreased significantly from baseline at three hours after both running $(p<0.01)$ and cycling $(p<0.05)$ and was still decreased the day after running $(p<0.05)$. No change in CTX-I levels was seen during rest. This suggests that exercise acutely reduces bone-turnover.

C2M was decreased at 1 hour after running (Change: $-9.4 \%, 95 \% \mathrm{Cl}:-18.4--1.0$, $\mathrm{p}<0.05)$, but was found to be increased from baseline at 2 hours after cycling (Change: 19.0\%, 95\%Cl: 6.0-32.0, p<0.01). C2M decreased below baseline 24 hours after running (Change: $-9.4 \%, 95 \% \mathrm{Cl}:-16.1-2.7, \mathrm{p}<0.01)$. This suggests that the load from cycling and running, respectively, affects tissues containing type II collagen differently.

C3M was decreased at 2 hours after cycling (Change: $-6.3 \%, 95 \% \mathrm{Cl}:-12.1--0.5$, $\mathrm{p}<0.05)$ and 3 hours after running (Change: $-7.6 \%, 95 \% \mathrm{Cl}:-16.4-0.8, p<0.05)$, and C3M levels had returned towards baseline after 24 hours.

C6M was increased at 1 hour after initiating rest and decreased 1 and 2 hours after running $(p<0.05)$ and cycling $(p<0.01)$, and C6M levels had returned to baseline after 24 hours. These results indicate reduced enzymatic degradation of collagens type III and VI following exercise.

The variation in CTX-II was higher, compared with the serum-based markers. A trend of decreasing CTX-II in response to rest was observed, but no significant changes were seen in response to exercise.

\begin{tabular}{lcc}
\hline Group & $\begin{array}{c}\text { Cycling/Resting } \\
(\mathrm{N}=20)\end{array}$ & $\begin{array}{c}\text { Running } \\
(\mathrm{N}=15)\end{array}$ \\
\hline Mean age, years (SD) & $61.8(9.1)$ & $61.9(7.5)$ \\
Male sex, $\mathrm{n}(\%)$ & $5(25)$ & $4(26.6)$ \\
Mean BMI $\left(\mathrm{kg} / \mathrm{m}^{2}\right)(\mathrm{SD})$ & $26.3(3.4)$ & $26.5(3.6)$ \\
Baseline KL-grade, $\mathrm{n}(\%)$ & $1: 3(15.0)$ & $1: 2(13.3)$ \\
& $2: 8(40.0)$ & $2: 8(53.3)$ \\
& $3: 9(45.0)$ & $3: 5(33.3)$ \\
\hline
\end{tabular}
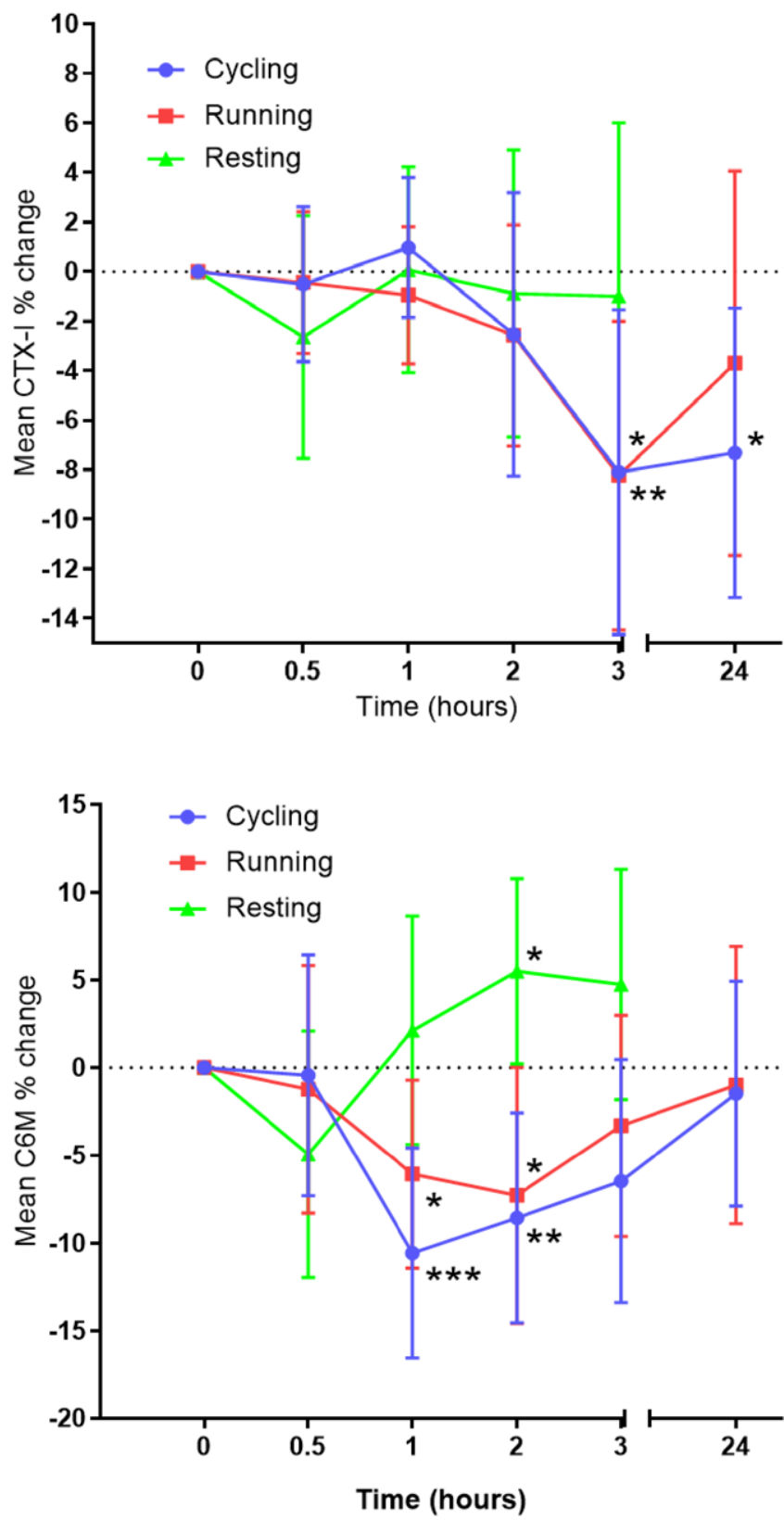

Conclusion: Cycling and running acutely influenced markers of type I-III and VI collagen. The results suggest no harmful effects on bone and cartilage in OA. The sensitivity of biomarkers to physical activity and inactivity is important to take into account, when using them in clinical research.

Disclosure of Interests: Jonathan Bjerre-Bastos: None declared, Henning Bay Nielsen: None declared, Abigail Mackey: None declared, Morten Karsdal Shareholder of: Nordic Bioscience A/S., Employee of: Full time employee at Nordic Bioscience A/S., Anne-Christine Bay-Jensen Shareholder of: Nordic Bioscience A/S, Employee of: Full time employee at Nordic Bioscience A/S., Jeppe Ragnar Andersen Shareholder of: Nordic Bioscience A/S., Employee of: Full time employee of Nordic Bioscience., Mikael Boesen Consultant of: AbbVie, AstraZeneca, Eli Lilly, Esaote, Glenmark, Novartis, Pfizer, UCB, Paid instructor for: IAG, Image Analysis Group, AbbVie, Eli Lilly, AstraZeneca, esaote, Glenmark, Novartis, Pfizer, UCB (scientific advisor)., Speakers bureau: Eli Lilly, Esaote, Novartis, Pfizer, UCB, Yi He Employee of: YH is a full time employee of Nordic Bioscience A/S, Asger Reinstrup Bihlet Shareholder of: Nordic Bioscience A/S.

DOI: 10.1136/annrheumdis-2020-eular.1809 